\title{
Resistance to external sulfate attack - Comparison of two alkali-activated binders
}

\author{
Miroslav Komljenović ${ }^{1, *}$, Nataša Džunuzović ${ }^{1}$, and Violeta Nikolić $^{1}$ \\ ${ }^{1}$ Institute for Multidisciplinary Research, University of Belgrade, Kneza Višeslava 1, 11000 Belgrade, \\ Serbia
}

\begin{abstract}
Durability of binders, mortars and concretes in aggressive environments is of crucial importance for their commercial application. In this paper the resistance to external sulfate attack of two different alkaliactivated binders (AABs), based either on blast furnace slag (BFS) or fly ash/blast furnace slag (FA/BFS) blend, was compared with two different commercially available Portland cement (CEM II) blended either with BFS or with FA and BFS. Comparison of sulfate resistance was based on compressive strength testing (the loss of strength) of mortar samples exposed to sodium sulfate attack up to 180 days and samples cured under controlled conditions for the same period of time. Furthermore, the evolution of microstructure of alkali-activated binders and $\mathrm{pH}$ of sodium silicate solution during testing were also analyzed. Despite different gel chemistry being involved, both alkali-activated binders based either on BFS or FA/BFS blend showed excellent resistance to external sulfate attack and even better than selected Portland cements tested under the same experimental conditions.
\end{abstract}

\section{Introduction}

Durability of concrete structures during long-term exploitation is of key importance for their safe and efficient functioning and it is determined by its ability to resist chemical attack, weathering action, abrasion, or any other process of deterioration. Chemical reactions that can alter the cement paste properties are one of the fundamental causes of concrete degradation.

The external sulfate attack, as an important process of concrete degradation, might occur due the presence of sulfate ions in soils, underground waters, sea water or industrial waste waters [1-2]. Generally, sulfates are harmful to Portland cement-based structures, but their detrimental impact depends on the type of cement used, quality of concrete, concrete exploiting conditions, nature and concentration of aggressive sulfate solution, as well as presence of different salts and/or cations in sulfate solution. Expansion, cracking, spalling, strength loss, and ultimately disintegration are usually recognized as consequences of external sulfate attack.

In the last few decades alkali-activated binders (AABs) have drawn attention of scientific and professional community as promising alternative to Portland cement. AABs

*Corresponding author: miroslav.komljenovic@imsi.rs 
are formed as products of chemical reaction between calcium silicate- or alumino-silicatebased solid precursors and alkali activator. The entire range of natural and synthetic materials can be used as solid precursors for this purpose [3]. The most promising solid precursors for large-scale applications are industrial wastes/by-products such as fly ash (FA) from thermal power plants and blast furnace slag (BFS) from pig iron production. In order to underpin the predicted future role, AABs are expected to meet the requirements specified for Portland cements in terms of quality and durability [4-5].

Despite the fact that the external sulfate attack on Portland cement was intensively studied, the experimental conditions applied were usually incomparable due to the type of samples used (paste, mortar and/or concrete), w/c ratio, sample shape (prisms, cubes or cylinders) and dimension, curing conditions prior to sulfate attack (water, saturated limewater, temperature, time, humidity), aggressive medium type and concentration, as well as conditions of sulfate attack (full or partial immersion of samples, $\mathrm{pH}$ and $\mathrm{SO}_{4}{ }^{2-}$ concentration control, time, solution agitation, recycling, etc.) [6].

Different methods for monitoring the process and kinetics of sulfate attack were also used: expansion, mass loss, porosity, as well as flexural and/or compressive strength. The ASTM C1012 method was frequently used as internationally recognized and standardized test procedure. However, this method was often criticized due to its limitation i.e., orientation to expansion effect. On the other hand, there is no appropriate European (EN) standard available. Therefore, the experimental conditions for testing the resistance of Portland cement systems to external sulfate attack or the pass/fail criteria that should be fulfilled are still elusive.

The main goal of this paper is to compare the resistance to external sulfate attack $(5 \%$ $\mathrm{Na}_{2} \mathrm{SO}_{4}$ ) of two chemically different alkali-activated binders with commercially available Portland cements. Alkali-activated binders are based either on blast furnace slag (BFS) or fly ash/blast furnace slag (FA/BFS) blend. The method used within this investigation is focused on the strength loss, as recommended by the State of the art report CEN/TR 15697 [7] related to the performance testing for sulfate resistance of cement. Furthermore, the evolution of microstructure of alkali-activated binders and $\mathrm{pH}$ of sodium silicate solution during testing are also analyzed.

For comparison of mechanical characteristics after exposure to a sulfate solution, Portland cement (CEM I - Ordinary Portland Cement, OPC) was usually used as a reference material. However, CEM I is well-known as highly susceptible to the influence of $\mathrm{Na}_{2} \mathrm{SO}_{4}$ solution. Therefore, commercially available Portland cement (CEM II), blended either with BFS or with FA and BFS, were used as benchmark materials in this work. Finally, all binders were tested under the same experimental conditions $[6,8]$ making this comparison more reliable.

\section{Materials and methods}

\subsection{Materials}

In this study the following materials were used:

1. Blast furnace slag (BFS) from pig iron production - "Železara Smederevo" d.o.o., Smederevo, Serbia

2. Fly ash (FA) from thermal power plant - "Morava", Svilajnac, Serbia

3. Portland-slag cement (CEM II/A-S 42.5N) - from cement producer Kosjerić, Serbia.

4. Portland-composite cement (CEM II/B-M (S-L) 42.5N) - from cement producer "CRH Srbija", d.o.o., Novi Popovac, Serbia 
5. Sodium silicate - water glass $\left(\mathrm{Na}_{2} \mathrm{O} \cdot \mathrm{nSiO}_{2}\right)$ - "Galenika-Magmasil" d.o.o., Zemun, Serbia.

6. Sodium hydroxide $(99 \% \mathrm{NaOH})$ - VWR, Germany.

7. Sodium sulfate $\left(99 \% \mathrm{Na}_{2} \mathrm{SO}_{4}\right)$ - Superlab, Beograd, Serbia.

Table 1. Chemical composition of initial materials.

\begin{tabular}{|c|c|c|c|c|c|c|c|c|c|c|}
\hline & $\mathrm{SiO}_{2}$ & $\mathrm{Al}_{2} \mathbf{O}_{3}$ & $\mathrm{Fe}_{2} \mathbf{O}_{3}$ & $\mathbf{C a O}$ & $\mathbf{M g O}$ & $\mathbf{S O}_{3}$ & $\mathbf{S}$ & $\mathbf{N a}_{2} \mathbf{O}$ & $\mathbf{K}_{2} \mathbf{O}$ & $\begin{array}{c}\mathbf{L O I} \mathbf{~ a t} \\
\mathbf{1 0 0 0}{ }^{\circ} \mathbf{C}\end{array}$ \\
\hline $\mathbf{B F S}$ & 37.50 & 7.27 & 0.73 & 38.48 & 10.86 & 0.39 & 1.51 & 0.54 & 0.26 & 2.13 \\
\hline $\mathbf{F A}$ & 55.23 & 21.43 & 7.42 & 7.94 & 2.61 & 0.81 & - & - & - & 1.66 \\
\hline $\begin{array}{c}\mathbf{C E M} \\
\text { II/A-S }\end{array}$ & 21.70 & 4.62 & 2.98 & 62.53 & 1.56 & 2.44 & 0.00 & 0.45 & 0.60 & 2.80 \\
\hline $\begin{array}{c}\mathbf{C E M} \\
\text { II/B-M }\end{array}$ & 21.33 & 5.49 & 2.62 & 58.67 & 3.01 & 2.27 & - & - & - & 4.41 \\
\hline
\end{tabular}

\subsection{Preparation of mortar and paste samples}

Alkali-activated binders (AABs), based either on blast furnace slag (BFS) or fly ash/blast furnace slag $(\mathrm{FA} / \mathrm{BFS}=1 / 1)$ blend, were prepared with sodium silicate solution. Modulus $\left(\mathrm{SiO}_{2} / \mathrm{Na}_{2} \mathrm{O}\right.$ mass ratio) of sodium silicate used was 1.5 and it was adjusted by adding sodium hydroxide. The concentration of the activator with respect to the dry mass of solid precursors (SP: BFS or FA/BFS) was $4 \%$ of $\mathrm{Na}_{2} \mathrm{O}$ in the case of $\mathrm{BFS}$ and $10 \%$ of $\mathrm{Na}_{2} \mathrm{O}$ in the case of FA/BFS blend.

Mortars of alkali-activated binders were prepared by mixing sodium silicate solution with SP and standard sand [SRPS EN 196-1 (2008)]. SP/sand ratio was 1/3. For Portland cement mortars water/cement $(\mathrm{w} / \mathrm{c})$ ratio was 0.5 . In order to have the same consistency as benchmark material (CEM II) the optimal amount of water required for alkali-activated binder mortars was determined by flow table test. Therefore, water/binder $(\mathrm{w} / \mathrm{b})$ ratio was 0.43 in the case of BFS and 0.39 in the case of FA/BFS blend. Water in w/b ratio included water from sodium silicate solution and water added for appropriate consistency, while binder in $\mathrm{w} / \mathrm{b}$ included SP and solid part of the activator. Three mortar prisms $(40 \mathrm{~mm} \times 40$ $\mathrm{mm} \times 160 \mathrm{~mm}$ ) were prepared for each mixture according to the Serbian standard SRPS EN 196-1 (2008), which is in compliance with the European EN 196-1 standard.

Pastes of alkali-activated binders were prepared by mixing sodium silicate solution with SP (in the same proportion as in the case of mortars) and water. Water/binder (w/b) ratio was 0.28 in the case of BFS and 0.34 in the case of FA/BFS blend. Dimensions of paste samples were $25 \mathrm{~mm} \times 25 \mathrm{~mm} \times 30 \mathrm{~mm}$. For SEM/EDS analysis pastes were prepared by immersing the samples in isopropyl alcohol for $24 \mathrm{~h}$ and and then dried at $50{ }^{\circ} \mathrm{C}$ for 60 minutes.

For the first $24 \mathrm{~h}$ mortar samples were cured in molds in a humid chamber $\left(20 \pm 2^{\circ} \mathrm{C}\right.$ and R.H. $\geq 90 \%$ ). and after demolding the initial curing was continued up to 28 days also in a humid chamber. After the period of initial curing mortar samples were either exposed to external sulfate attack $\left(5 \% \mathrm{Na}_{2} \mathrm{SO}_{4}\right.$ solution) or further cured in a humid chamber (reference samples). Paste samples were cured/exposed under the same experimental conditions.

$5 \% \mathrm{Na}_{2} \mathrm{SO}_{4}$ solution was prepared by dissolving $\mathrm{Na}_{2} \mathrm{SO}_{4}$ in distilled water and plased in 101 plastic containers. Mortar samples were placed on plastic carriers and completely immersed in the solution thus allowing all surfaces to be in contact with the aggressive sulfate solution. Sulfate solution/mortar samples mass ratio was $\sim 4$. Complete replacement 
of $\mathrm{Na}_{2} \mathrm{SO}_{4}$ solution was performed every 30 days over anticipated period of external sulfate attack testing.

\subsection{Methods of characterization}

Chemical composition of the initial FA and BFS samples was determined by classic chemical analysis - alkali melting, and CEM II according to the Serbian standard SRPS EN 196-2 (2008).

Compressive and flexural strengths of alkali-activated binders and CEM II were tested according to the SRPS EN 196-1 (2008) standard which is in compliance with the European EN 196-1 standard, using Controls model 65-L1300/P (Italy) device.

Microstructural characterization was carried out on alkali-activated binders pastes by scanning electron microscopy (SEM) method using VEGA TS 5130 MM Tescan electron microscope. Energy dispersive X-ray spectroscopy (EDS) was done by INCAPentaFET-x3 (Oxford Instruments). Prior to the SEM-EDS analysis, samples were polished and Aucoated. In order to obtain more accurate binder matrix composition during the EDS analysis the unreacted FA or BFS particles visible on the sample surface were deliberately excluded. The results of EDS analysis represent the average values of 20-30 individual EDS analysis for each examined sample.

The $\mathrm{pH}$ values of $\mathrm{Na}_{2} \mathrm{SO}_{4}$ solution during the testing period were measured by $\mathrm{pH}$-meter (pHTestr30, Eutech Instruments, Holland).

\section{Results and discussion}

\subsection{Compressive strength}

The results of mortar compressive strength testing of alkali-activated binders and corresponding benchmark CEM II are given in Fig. 1. Alkali-activated BFS did not show any sign of deterioration after exposure to external sulfate attack over a period of 90 days (Fig. 1a). On the contrary, the samples of alkali-activated BFS exposed to sodium sulfate solution showed higher strength increase when compared to the reference samples cured in a humid chamber for the same period of time. This means that the sodium sulfate solution actually acted as an alkali activator rather than the harmful substance. At the same time, the corresponding benchmark material Portland-slag cement (CEM II/A-S 42.5N) showed significant strength decrease after 60 days of exposure to external sulfate attack i.e. the beginning of significant deterioration (Fig. 1c).

Alkali-activated FA/BFS blend also did not show significant sign of deterioration even after exposure to external sulfate attack over a period of 180 days (Fig. 1b). The samples of alkali-activated FA/BFS blend exposed to sodium sulfate solution showed strength increase but at somewhat slower rate when compared to the reference samples cured in a humid chamber for the same period of time. This means that the sodium sulfate solution only inhibited the reaction of alkali activation to a certain extent, but definitely did not act as the harmful substance. At the same time, the corresponding benchmark material Portlandcomposite cement (CEM II/B-M (S-L) 42.5N) showed significant strength decrease after 90 days of exposure to external sulfate attack i.e. the beginning of significant deterioration (Fig. 1d).

Better behavior of alkali-activated binders in aggressive sulfate environment is also visible when relative mortar compressive strength (samples exposed to sulfate attack in respect to the reference samples of same age) of alkali-activated binders and benchmark 
CEM II are compared (Fig. 2). Therefore, it can be concluded that both alkali-activated binders based on BFS or FA/BFS blend showed remarkable resistance to external sulfate attack and better than corresponding Portland cement counterparts tested under the same experimental conditions.
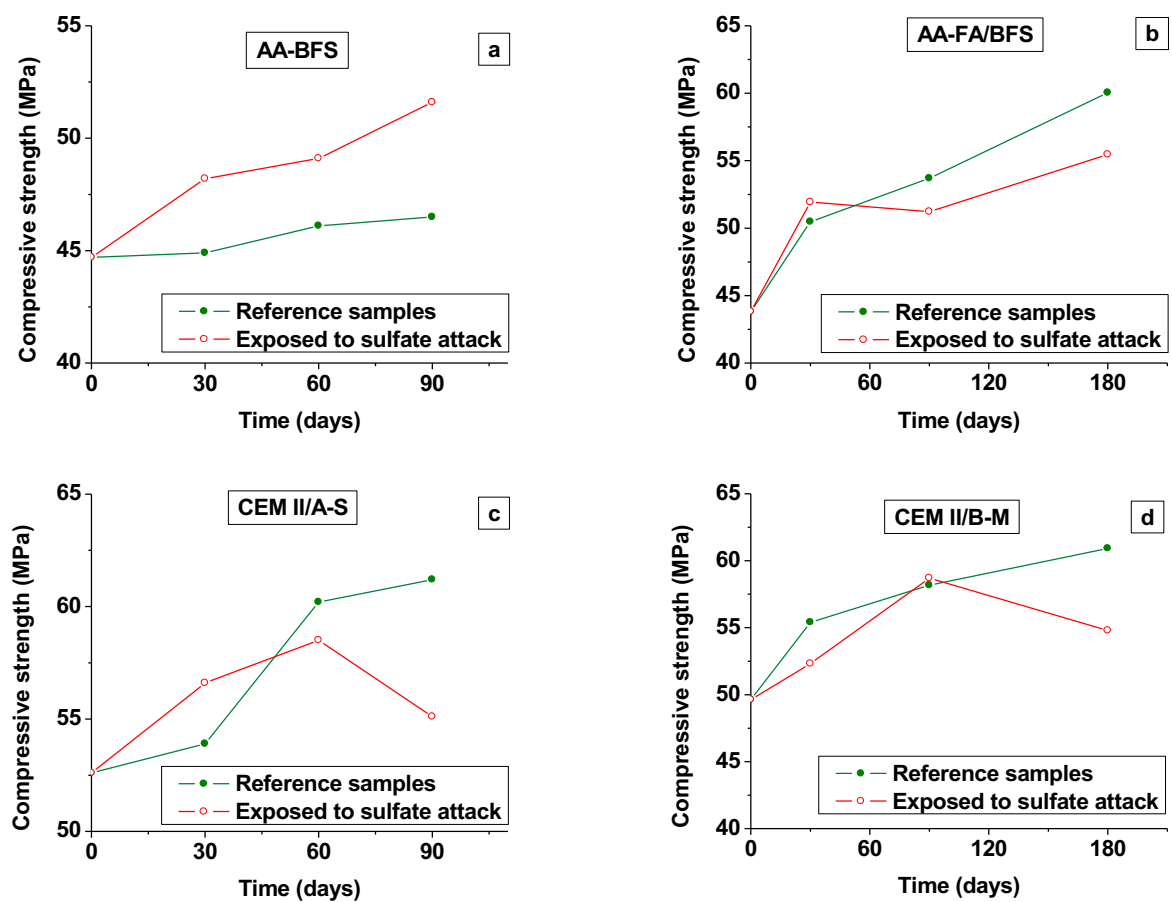

Fig. 1. Mortar compressive strength of alkali-activated binders and benchmark CEM II (reference samples and samples exposed to sulfate attack; a) Alkali-activated BFS; b) Alkali-activated FA/BFS blend; c) Portland-slag cement (CEM II/A-S 42.5N); d) Portland-composite cement (CEM II/B-M (SL) $42.5 \mathrm{~N})$; (adapted from $[6,8]$ ).
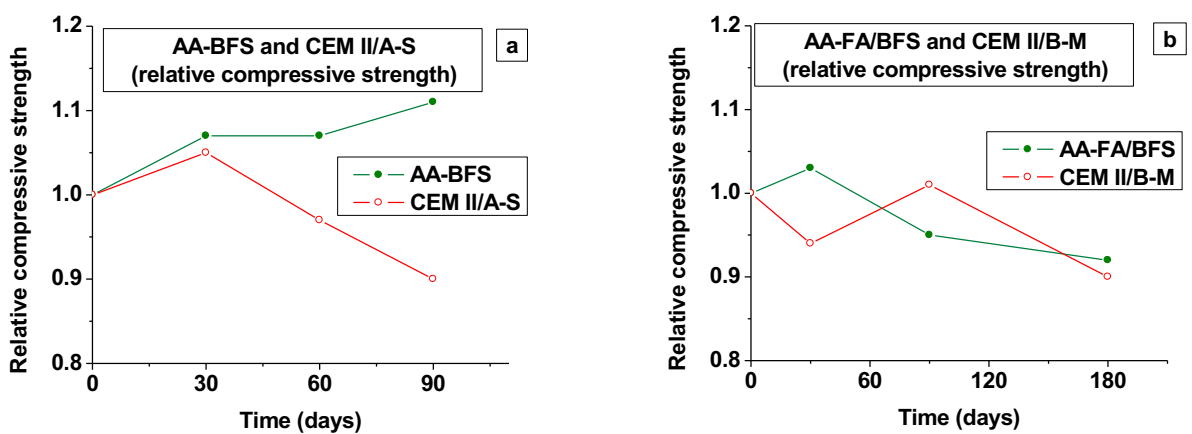

Fig. 2. Relative mortar compressive strength of alkali-activated binders and benchmark CEM II (samples exposed to sulfate attack in respect to the reference samples of same age); (adapted from $[6,8])$ 


\subsection{EDS analysis}

The results of microstructural (EDS) analysis of alkali-activated binders are given in Fig. 3.
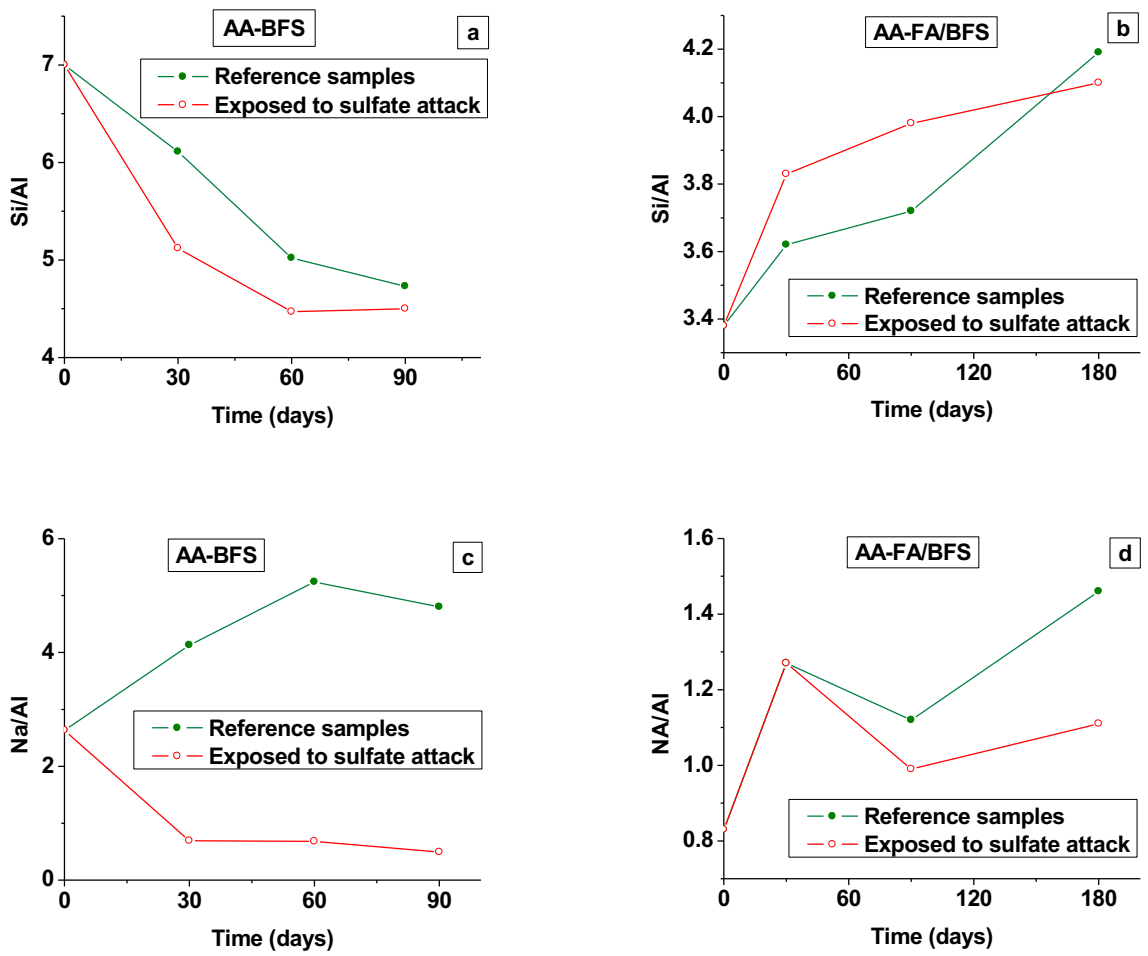

Fig. 3. EDS analyses of reference samples and samples exposed to sulfate attack (the average ratios of the main elements of alkali-activated binder matrix): a) AA-BFS; b) AA-FA/BFS blend; (adapted from $[6,8])$

The $\mathrm{Si} / \mathrm{Al}$ atomic ratio of alkali-activated $\mathrm{BFS}$ decreased throughout the whole period of 90 days of testing, whereby this ratio decreased at faster rate in samples exposed to external sulfate attack (Fig. 3a). In both cases this ratio was tending to the $\mathrm{Si} / \mathrm{Al}$ value of 4.5-4.7. Obviously, the decrease of the $\mathrm{Si} / \mathrm{Al}$ ratio was connected with the strength increase (Fig. 1a). On the other hand, the Si/Al atomic ratio of alkali-activated FA/BFS blend increased throughout the whole period of 180 days of testing, whereby in the initial period of 90 days this ratio increased at faster rate in samples exposed to external sulfate attack (Fig. 3b). In both cases this ratio was tending to the $\mathrm{Si} / \mathrm{Al}$ value of 4.1-4.2. In the case of FA/BFS blend the strength increase (Fig. 1b) was connected with the increase of the Si/Al ratio, confirming completely different gel chemistry being involved when compared with the alkali-activated BFS. It is well known that in the case of alkali-activated BFS the predominant reaction products are C-S-H or C-(A)-S-H gels [6], while in the case of FA/BFS blend the predominant reaction products are N-A-S-H or N-(C)-A-S-H gels [8].

$\mathrm{The} \mathrm{Na} / \mathrm{Al}$ atomic ratio of alkali-activated BFS samples exposed to external sulfate attack decreased throughout the whole period of 90 days of testing (Fig. 3c), most probably due to the sodium leaching. Obviously, sodium leaching did not cause any strength 
deterioration (Fig. 1a) since sodium can be replaced with $\mathrm{H}+$ or $\mathrm{H}_{3} \mathrm{O}^{+}$ions in gel structure without recordable structural damage. At the same time, the $\mathrm{Na} / \mathrm{Al}$ atomic ratio in the reference samples increased, probably due to the higher sodium uptake in the binder matrix in the same period. On the other hand, the $\mathrm{Na} / \mathrm{Al}$ atomic ratio of alkali-activated $\mathrm{FA} / \mathrm{BFS}$ blend increased after a period of 180 days of testing, both in reference samples and samples exposed to sulfate attack (Fig. 3d), confirming sodium being more tightly bound in the $\mathrm{N}$ A-S-H or N-(C)-A-S-H gels than in the C-S-H or C-(A)-S-H gels.

\section{$3.3 \mathrm{pH}$ of $\mathrm{Na}_{2} \mathrm{SO}_{4}$ solution}

The results of $\mathrm{pH}$ of the initial sodium sulfate solution and throughout the whole period of testing are given in Table 2.

Obviously the slightly acidic $\mathrm{pH}$ (6-6.7) of the initial sodium sulfate solution shifted to highly alkaline $\mathrm{pH}(>11)$ after first 30 days of testing and remained almost constant after further testing. One should have in mind that sodium sulfate solution was completely replaced each 30 days, whereby continuous sodium leaching from alkali-activated binder matrix was confirmed by highly alkaline $\mathrm{pH}$.

Table 2. $\mathrm{pH}$ of $\mathrm{Na}_{2} \mathrm{SO}_{4}$ solution during the investigation.

\begin{tabular}{|c|c|c|c|c|c|}
\hline Sample & Initial pH & $\begin{array}{c}\text { After 30 } \\
\text { days }\end{array}$ & $\begin{array}{c}\text { After 60 } \\
\text { days }\end{array}$ & $\begin{array}{c}\text { After 90 } \\
\text { days }\end{array}$ & $\begin{array}{c}\text { After 180 } \\
\text { days }\end{array}$ \\
\hline AA-BFS & 6.63 & 11.44 & 11.54 & 11.60 & - \\
\hline AA-FA/BFS & 6.04 & 13.11 & - & 11.30 & 11.25 \\
\hline
\end{tabular}

\section{Conclusions}

Based on the results presented the following conclusion can be drawn:

Despite different gel chemistry being involved, both alkali-activated binders based on BFS or FA/BFS blend showed exceptional resistance to external sulfate attack and even better than corresponding Portland cement CEM II counterparts tested under the same experimental conditions.

Alkali-activated binders showed better resistance to external sulfate attack than Portland cements due to unavailability of aluminum to react with sulfates since aluminum was tightly bound in the C-(A)-S-H, N-A-S-H, N-(C)-A-S-H, and/or hydrotalcite gel.

This research was financially supported by the Ministry of Education, Science and Technological Development of the Republic of Serbia through project TR 34026.

\section{References}

1. F.P. Glasser, J. Marchand, E. Samson, Cem. Concr. Res. 38, 226-46 (2008)

2. A. Neville, Cem. Concr. Res. 34, 1275-96 (2004)

3. M. Komljenović, Handbook of Alkali-Activated Cements, Mortars, and Concretes, 171-217 (Woodhead Publishing, 2014).

4. M. Whittaker, L. Black, Adv. Cem. Res. 27(9), 532-545 (2015)

5. W.G.V. Saavedra, D.E. Angulo, R.M. de Gutiérrez, J. Mater. Civ. Eng. 28(12), 04016148 (2016) 
6. M. Komljenović, Z. Baščarević, N. Marjanović, V. Nikolić, Constr. Build. Mat. 49, 3139 (2013)

7. CEN/TR 15697 (2008)

8. N. Džunuzović, M. Komljenović, V. Nikolić, T. Ivanović, Constr. Build. Mat. 157 737-747 (2017) 